\title{
LOS MALECUS CONTRA CRISTÓBAL COLÓN: ¿ANACRONISMO O RETRADICIONALIZACIÓN?
}

\author{
The Malecus against Christopher Columbus: anachronism or \\ retraditionalization
}

\author{
Carlos Sánchez Avendaño*
}

\begin{abstract}
RESUMEN
En este artículo se comentan dos textos de la tradición oral malecu relativos al contacto y enfrentamiento de este pueblo indocostarricense con los conquistadores españoles encabezados por Cristóbal Colón. El primer texto parece ser una reelaboración de un relato sobre el período de la segunda mitad del siglo XIX en el cual los malecus se vieron perseguidos por huleros de origen hispano que invadieron su territorio. El segundo relato muy posiblemente se construyó a partir de información recientemente adquirida acerca de los pueblos indígenas actuales, pero contiene trazos de probables tradiciones orales anteriores. En ambos casos, se toman esquemas narrativos antiguos a los que se les incorpora información de diversos momentos históricos, por lo cual resultan, desde una óptica historiográfica hispanocostarricense, anacrónicos. Se propone, no obstante, que en realidad estamos ante un proceso de retradicionalización.
\end{abstract}

Palabras clave: Tradición oral, malecu, retradicionalización.

\begin{abstract}
In this article, two texts from Malecu oral tradition related to the contact and confrontation of this Costa Rican indigenous people with the Spanish conquerors led by Christopher Columbus are commented. The first text seems to be a reformulation of a story from the second half of the XIX century in which the Malecu were chased by rubber makers of Hispanic origin who invaded their territory. The second text is very probably constructed from information recently acquired concerning current indigenous peoples, but it contains traces of possible former oral traditions. In both cases, information from different historic periods are incorporated in old narrative outlines, resulting, therefore, in an anachronistic one, from a Hispanic historiographic perspective. Our proposal, however, is that this is actually due to a process of retraditionalization.
\end{abstract}

Key Words: Oral tradition, Malecu, retraditionalization.

*Universidad de Costa Rica. Escuela de Filología, Lingüística y Literatura. Costa Rica.

Correo electrónico: tocumara@yahoo.es, ORCID: https://orcid.org/0000-0001-5029-2898

Recepción: 18/09/2018. Aceptación: 25/02/2019. 


\section{Introducción}

Las versiones peor documentadas en relación con los períodos de la Conquista y la Colonia del actual territorio costarricense, y en particular sobre los procesos de guerra y sometimiento a los que se vieron enfrentadas las poblaciones originarias, son precisamente las propias de los pueblos indígenas. Hasta donde nuestro conocimiento alcanza, en lo concerniente a textos recogidos en la lengua autóctona de las comunidades, únicamente se han publicado dos textos bruncas en Constenla y Maroto (1979) y otros dos textos malecus en Betancourt y Constenla (1981).

En este sentido, este trabajo constituye un pequeño aporte encaminado a subsanar este vacío, al presentar, en malecu y en su respectiva traducción al español, dos textos: uno relativo al supuesto enfrentamiento de los malecus con Cristóbal Colón y los conquistadores españoles que lo acompañaban, y otro relacionado con la participación de los malecus en una presunta batalla que habrían sostenido todos los actuales pueblos indocostarricenses contra Colón y su ejército.

Además de recoger ambas versiones - tarea valiosa per se para aproximarnos a la visión de los pueblos originarios acerca de eventos acaecidos hace más de cinco siglos cuyas repercusiones siguen presentes-, se proponen algunas explicaciones de cómo tales textos han llegado hasta la actualidad y cómo deben abordarse en tanto reelaboración o reinterpretación de un hito que cambió el orden social prevaleciente, aunque a primera vista pudieran parecer recuentos anacrónicos de acontecimientos, circunstancias y protagonistas propios de diversos momentos históricos. 


\section{El contacto de los malecus con personas de cultura y lengua española: la versión exocomunitaria}

El contacto de los malecus (denominados "guatusos" en las crónicas coloniales y en otros documentos hasta época reciente) con el grupo conquistador de cultura y lengua hispánica se caracteriza por varios factores que lo tornan sui géneris en el contexto centroamericano. En lo que atañe al tema del presente trabajo, conviene resaltar tres de ellos: se trata del último pueblo amerindio del actual territorio costarricense con el que entraron en relación los españoles, ya a finales de la Colonia; nunca fueron conquistados ni sometidos a los distintos regímenes de explotación colonial; su contacto real y duradero con personas de lengua y cultura hispanas se empezó a producir ya bien entrada la segunda mitad del siglo XIX (Castillo, 2005; Constela, 1988).

Entre las circunstancias que confluyeron en que no se verificara la conquista europea del territorio malecu, Castillo (2004) destaca el aislamiento de su hábitat ancestral (la cuenca del río Frío), las condiciones climáticas adversas del entorno, su densa cobertura forestal y la barrera natural creada por los sistemas montañosos que rodean la llanura. Asimismo, debe subrayarse que la región se hallaba en la periferia en relación con las áreas de poblamiento español en el Valle Central y en la Península de Nicoya; que hasta finales del período colonial los conquistadores desconocieron de su existencia; y que imperaba el poco estímulo por explorar la zona debido a que se consideraba que carecía de minerales y estaba habitada por pocos nativos.

Las primeras referencias a indígenas asentados propiamente en la cuenca del río Frío datan de la década de 1750, cuando el misionero franciscano José A. Zepeda informa haber habitado por varios meses entre los nativos de tal región. Posteriormente, la queja interpuesta 
por vecinos de Esparza, Bagaces y Cañas con respecto a la desaparición de ganado y caballos, así como los indicios de que estos fueron llevados hacia las montañas de la Guatusa, al noroeste de Esparza, se consideraron como apoyo de lo reportado por Zepeda. Por ello, José Miguel Martínez, clérigo de Esparza, notificó sobre ambos acontecimientos, lo que resultó en que las autoridades del país lo encargaran de buscar a tales indígenas (Castillo, 2004). La expedición a su cargo encontró osamentas de res en algunos sitios habitados, pero no a sus residentes, quienes habían abandonado el lugar al enterarse de la visita de los forasteros mediante un aviso de los nativos del pueblo de Barva (Fernández, 1907).

Para Solórzano (1997), esta prevención de parte de los nativos de Barva constituye evidencia de que existía algún tipo de contacto entre los indígenas de la región norte no conquistada y los indígenas del Valle Central. En relación con esto, las montañas de la Guatusa posiblemente constituían una zona de refugio para los nativos escapados de otras partes del país (Fernández, 1907; Solórzano, 1997), como también se evidenció con la captura de dos indígenas de Pacaca y cuatro de Boruca en una expedición posterior realizada por vecinos de Esparza, en la cual uno de estos informó tener un hermano en dichas montañas. En todo caso, es poco probable que en el sitio explorado habitaran los malecus, puesto que la religión malecu no permitía el consumo de venados y era muy probable que las reses fueran asimiladas a estos por poseer cuernos (Constenla, 1988), así que no habrían sido ellos quienes hurtaron los animales.

Algunos años después, fray Tomás López se embarcó en el río Frío con el fin de contactar a los nativos de la región; no obstante, fracasó en su propósito debido a que sus guías indígenas se negaron a proseguir el viaje al divisar las balsas de los locales. Las subsiguientes cuatro expediciones que se organizaron también resultaron infructuosas; sin embargo, en la segunda de ellas, acaecida en 1783 bajo el mando de Esteban Lorenzo de 
Tristán, obispo de Nicaragua y Costa Rica, los expedicionarios pudieron entrar, según su propia crónica, al "río de los Monos", considerado en Betancourt y Constenla (1981) como el actual río La Muerte, tributario del río Frío. En el viaje divisaron a lo lejos a tres indígenas, quienes no respondieron al llamado de los intérpretes llevados por los religiosos.

Según la crónica colonial (Betancourt y Constenla, 1981), fray Tomás López decidió proseguir en la búsqueda de tales indígenas acompañado únicamente de los tres intérpretes. Para su desgracia, luego de un día de navegación, fueron atacados con flechas. Como resultado, uno de estos resultó herido, de manera que López les dio la orden a los otros dos de que regresaran en el bote y lo dejaran ahí. Los intérpretes lograron escapar y unirse al grupo del obispo Tristán, a quienes les contaron que López se había quedado entre los indígenas.

El lingüista Adolfo Constenla Umaña recogió en 1970 dos textos malecus que parecen referirse a este mismo acontecimiento (Betancourt y Constenla, 1981). En uno de estos, al territorio malecu llegaron dos chiúti -etnónimo con que en malecu se denomina a las personas que no son de origen indígena-. Estos construyeron una pequeña casa para alojarse, pero al poco tiempo llegaron los malecus, los mataron con flechas -ignorando que uno de ellos era un sacerdote (en la narración se emplea el hispanismo "pádre")- y destruyeron el bote en el que estos viajaban, así como sus provisiones de alimentos (en cumplimiento de las normas de conducta regulares para los antiguos malecus: deshacerse de las pertenencias de quienes mueren mal y, por lo tanto, se condenan, por lo que se requiere destruir todo lo que pueda contaminar a las demás personas). Según el narrador, los malecus interpretaron que tales individuos llegaron con la intención de matarlos, así que se les adelantaron. Los restos del bote y de las cosas se fueron flotando por el río Frío, lo que sirvió de evidencia para los 
otros expedicionarios de que a sus compañeros los habían matado. Este acontecimiento desencadenó una guerra mortal entre ambos grupos.

En el segundo texto, el asesinato del sacerdote ocurre en el río La muerte. Este llegó solo con unas gallinas, a las que amarró en un palenque como regalo, tras lo cual se retiró a su ranchito. Los malecus oyeron el cacareo y, cuando vieron las gallinas, pensaron que se parecían al rey del zopilote -un animal considerado inmundo por ellos-, por lo que las mataron (del texto se infiere que el sacerdote había cometido una grave afrenta). Tras comentar que la intención del sacerdote era que las gallinas se reprodujeran para beneficio de los malecus, se cuenta que este regresó y fue asesinado a flechazos, pese a que gritó que no lo mataran y a que algunos de los malecus presentes dijeron que no lo siguieran asaeteando, pues seguramente "el pobre" les llevaba "cositas" para ayudarlos.

Ciertamente, tal y como se afirma en Betancourt y Constenla, esta narración incorpora pormenores que con toda probabilidad fueron añadidos posteriormente, tales como identificar al forastero como "pádre" (en el sentido de sacerdote), aclarar que las aves que llevaba eran en realidad gallinas y no reyes del zopilote, así como concebir este suceso como causal de la guerra entre malecus e hispanos. Además, los comentarios del narrador acerca de las verdaderas y loables intenciones del sacerdote dejan en evidencia su filtro interpretativo contemporáneo. De tratarse de una narración antigua, transmitida desde la época de los acontecimientos de finales del siglo XVIII -como sospecha Constenla-, es claro que los textos sufrieron modificaciones conforme los malecus tuvieron mayor contacto con la cultura hispana.

En suma, es probable que el contacto de los malecus con los individuos de cultura y lengua española fuera escaso o nulo, al menos hasta la segunda mitad del siglo XIX, a juzgar por la falta de referencias sobre su existencia en los documentos de las distintas épocas y por 
los datos presentes en la misma tradición oral de este pueblo (Castillo, 2004; Constenla, 1988). En este sentido, según Constenla (1988), las referencias más probablemente correctas acerca de su existencia datan de las expediciones realizadas en 1778 y 1783 , y luego no es sino hasta 1856 cuando se describe con mayor detalle su cultura material.

Esta situación cambió radicalmente en el período comprendido entre 1868 y 1889 , cuando los malecus estuvieron a punto de ser exterminados por los huleros que incursionaban en el territorio costarricense para apoderarse del caucho, una vez que el mercado internacional empezó a demandar grandes cantidades de esta materia prima y debido a que, tras el agotamiento de los árboles de hule en las áreas más accesibles, la región del río Frío se perfiló como una zona ideal para la explotación de esta materia, empleada en la fabricación de empaques, neumáticos, correas e incluso aislantes de cable (Boza y Solórzano, 2000; Castillo, 2004; Edelman, 1998).

Los malecus empleaban la corteza de estos árboles para la elaboración de su ropa y su goma para la iluminación, de modo que oponían resistencia a su extracción dentro de sus territorios. Ante el enfrentamiento constante con los malecus, los huleros optaron por matarlos o perseguirlos y capturarlos (sobre todo a los jóvenes) para venderlos como esclavos en Nicaragua, recurriendo al pretexto de que los llevaban a bautizar. En este país, eran utilizados como peones y sirvientes domésticos, de manera que la trata de esclavos se convirtió en una actividad lucrativa en sí misma (Castillo, 2004; Sapper, 1942), especialmente después de que empezó a escasear el hule debido a las malas técnicas de extracción, como lo explica León Fernández (1883) en una nota del texto de William Gabb incorporado en su libro y como lo expone con detalle Edelman (1998).

Una vez vencidos y muerto su jefe guerrero en una sangrienta batalla aparentemente desarrollada en el río La Muerte, cuyo nombre precisamente se deriva -según la tradición 
oral- de este acontecimiento, los huleros también adquirieron la costumbre de robar comida, utensilios y herramientas, y de violar y capturar a las mujeres, además de emplear a los hombres como esclavos para las actividades que se les presentaran en el momento, como la carga de materiales extraídos del bosque. Finalmente, las pestes y las enfermedades mermaron a quienes lograban sobrevivir ocultos en la montaña, en condiciones precarias: al aire libre, expuestos al ataque de animales salvajes, el frío, la lluvia y con una pésima alimentación (Castillo, 2004; Constenla, 1988; Porras, 1959; Sapper, 1942).

Existen textos de la tradición oral malecu acerca de lo acontecido durante la época de los huleros, en los cuales se relatan los terribles sucesos, las vejaciones, los asesinatos y el maltrato del que fueron víctimas, así como las actuaciones del obispo Bernardo Augusto Thiel en su favor. Algunas de ellas podrían haber sufrido -al igual que ocurrió con los textos sobre fray Tomás López- muchas modificaciones y adiciones con el pasar de los años, incluyendo datos que se habrían tomado de las crónicas y de la historiografía exocomunitaria, pero lo cierto es que constituyen la memoria endocomunitaria de un período que habría de cambiar el destino del pueblo malecu. Tomar en cuenta la existencia de estas narraciones resulta imprescindible para comprender el esquema narrativo de los textos que se comentarán más adelante.

\section{Tradición oral malecu sobre el enfrentamiento entre Cristóbal Colón y los malecus}

Si se considera que los malecus no sufrieron las consecuencias directas del proceso de conquista y colonización del actual territorio costarricense en los siglos XVI, XVII y XVIII, 
en principio no se esperaría que existieran narraciones tradicionales malecus sobre el período de la Conquista española y mucho menos acerca de Cristóbal Colón.

Sin embargo, hemos documentado dos textos al respecto, relatados por dos narradores ancianos distintos. En uno se atribuye la conquista del territorio malecu a un grupo de chiúti con Cristóbal Colón a la cabeza, en lo que parece ser un relato relacionado con los huleros, si bien la causa del exterminio de los malecus no es el caucho, sino el oro. En esta versión, los malecus logran salir airosos de dos enfrentamientos: en uno se defienden de los perros que acompañan a los conquistadores y en otro vencen a los mismos conquistadores, que los atacaban con armas, recurriendo a un artilugio mágico: unas plantas de pita que se adhieren a la piel de sus perseguidores. No obstante, ambas victorias parciales no logran cambiar el desenlace anunciado desde el inicio: la matanza de la que serían víctimas y el robo del oro.

En el segundo texto, se narra la guerra de los españoles liderados por Colón contra diferentes pueblos indígenas de la actual Costa Rica, evento en el que los malecus no participan, pues un cacique de otro grupo previene a los españoles sobre la belicosidad de aquellos y los convence de no intentar conquistarlos. A ello se suma que los malecus reciben un consejo de parte de un colócoma, un collar mágico parlante que aparece en otras historias tradicionales como instrumento que también previene a su portador acerca de posibles peligros (como la verdadera identidad felina de un individuo que aparenta ser humano y con quien el portador del collar anda en el bosque; ver Constenla y Castro, 2011). En este segundo relato, se insiste en que Colón no llegó a estar en territorio malecu, pero se describe con cierto detalle el enfrentamiento de los españoles con otros grupos como los bribris, los borucas, los cabécares, los guaymíes, los térrabas y los indígenas de Quitirrisí, en su afán de hacerse con el oro de estos. Además, se introduce una explicación de por qué los españoles no llegaron a territorio malecu. 
Debe destacarse que ambos textos se insertarían en el macrogénero textual malecu de los mausírrajáca maráma 'conversaciones', en el cual se incluyen las conversaciones sobre cualquier tema personal o grupal y las conversaciones sobre temas de trascendencia cultural, llamadas estas últimas maracunúca maráma 'lo que se ha escuchado', género que engloba las narraciones y las descripciones transmitidas por tradición y que gozan de un aprecio especial (Constenla, 1996).

Estas maracunúca maráma revelan el valor de la transmisión oral del conocimiento y del aprendizaje por medio de la escucha atenta y el interés por saber características de la cultura tradicional malecu. Constituían el vehículo fundamental de la educación en los valores, las creencias, la historia y, en general, el conocimiento de más alto nivel. Por la temática que tratan, las maracunúca maráma se dividen en ciclos que, entre otros, incluyen la cosmogonía, la transformación de la tierra y los relatos acerca de personajes ejemplares; la relación de los humanos con otros seres (como gigantes, duendes, animales) y los contactos con personas de origen hispano (Constenla, 1996). Todo lo narrado en este género discursivo era considerado verdadero.

A continuación presentamos los dos textos, tanto en la versión malecu como en la respectiva traducción idiomática al español. Para la versión malecu, se emplea la ortografía práctica de la lengua, cuyo diseño se expone en Constenla (1998). Además, en el caso del primer texto, junto a la versión malecu, se ofrece una traducción interlineal no especializada (en el tanto no se segmentan ni se etiquetan los morfemas o clíticos ni los valores semánticogramaticales de estos y otros elementos libres), la cual permite apreciar el significado aproximado en español de cada palabra malecu. El símbolo \& se emplea para indicar que a una palabra malecu corresponde una secuencia de palabras en la traducción aproximada al español. De cada versión en malecu se comentan algunos detalles léxico-gramaticales muy 
puntuales que permiten acercarse a la comprensión de la forma como se codifica la narración en la lengua y que, por ende, constituyen claves importantes de interpretación del texto.

El primer texto fue documentado con doña Alvina Muñoz Muñoz, adulta mayor del poblado conocido como Tonjibe, cuya edad actualmente ronda los 70 años y quien es considerada una de las grandes conocedoras de la tradición oral de su pueblo en la actualidad. Hemos segmentado el relato en cuatro secciones con base en los acontecimientos o circunstancias principales, con el único fin de mostrar cómo progresa temáticamente la narración.

En este texto, se aprecian estrategias léxicas y gramaticales diversas para acentuar la tensión narrativa. Por ejemplo, en lo que atañe al léxico, se emplea el cuantificador chí 'todo, toda, todos, todas' para enfatizar la afectación total de personas (chí malécu rricúe 'mató a todos los malecus') o de objetos (chí iconé ní rricúye oro 'les robó todo el oro'), así como el sustantivo chumá 'pobrecito' para referirse de forma conmiserativa a los malecus. En lo relativo a la gramática, la estrategia que más destaca es la duplicación de la raíz verbal. Este mecanismo ha sido descrito como un recurso con valor aspectual iterativo-durativo (Constenla, 1998), pero consideramos que en este texto se evidencia también cómo agrega un valor intensificador (malécu rricúecúe tonhé ‘vino matando y matando malecus' o 'vino haciendo una matazón de malecus'). Nótese cómo se emplea el hispanismo oro, debido a que no existe en la lengua malecu una palabra patrimonial para referirse a este metal (Tabla 1). La relevancia de este detalle se verá más adelante. 
Tabla 1. Texto 1, sobre la conquista de territorio malecu por Cristóbal Colón

\section{Texto 1}

Introducción: llegada de Colón, robo del oro y asesinato de malecus

Ní tonhé Cristóbal Colón itonhé Vino Cristóbal Colón

Este vino Cristóbal Colón vino

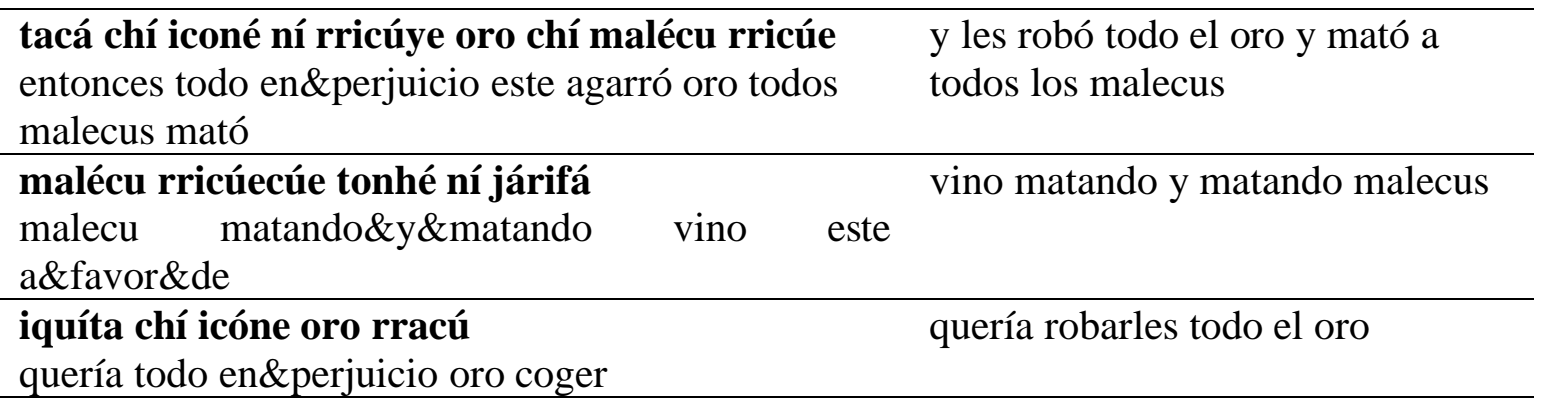

Primera persecución: persecución con perros y victoria de los malecus

tacá am ója chumá maráme y entonces otra vez los pobres

entonces otra\&vez corrieron pobre plural

tacá itué maráme córa córa quiója maráme $\quad$ y se fueron en medio del bosque

entonces fueron árbol árbol en\&medio plural

tacá jué itiní tué maráme y se fueron tras ellos

entonces en\&efecto tras\&ellos fueron plural
tacá jué itiní tué maráme
y se fueron tras ellos

entonces en\&efecto tras\&ellos fueron

tacá aúsiu itué maráme quirríjapurú tócufá aúsi y llevaban perros, demasiados

entonces perro\&con iban plural varios muchos perro perros

tacá ní malécu maráma rrítalóca y acechaban a los malecus

entonces este malecu plural acechando

ní ní malécu iquíta rrichiúchiúye querían que mordieran y

este este malecu querían moder\&y\&morder mordieran a los malecus

tacá ní iójacá maráma entonces corrieron

entonces este corrió plural

tacá ní ní puí rricuánhe y se fijaron

entonces este este bien vieron

tacá ní rrijatí maráme córa jacá paquéquirrí y cortaron cuatro palos

córa jacá rrijatí maráme

entonces este cortó plural palo cuatro palos cortó

plural

\begin{tabular}{ll}
\hline $\begin{array}{l}\text { tacá irriquí ijoquí iriafáranecá ta tiá maurá ní } \\
\text { rijué aúsi } \\
\text { entonces dijeron su\&cara esperémoslos para así } \\
\text { fuerte este golpear perro }\end{array}$ & $\begin{array}{l}\text { entonces dijeron: "esperémoslos } \\
\text { de frente para darles una buena } \\
\text { golpiza a los perros" }\end{array}$ \\
\hline $\begin{array}{l}\text { níni tuéca chumá maráma ta itiní iriarínhe } \\
\text { este\&es ir pobre plural y escondieron }\end{array}$ & $\begin{array}{l}\text { y entonces los pobrecitos se fueron } \\
\text { y se escondieron }\end{array}$ \\
\hline $\begin{array}{l}\text { aríquechá pá itonhé chumá maráme chí } \\
\text { ay ya vinieron pobre plural todo }\end{array}$ & $\begin{array}{l}\text { ¡ay! ya los pobrecitos vinieron } \\
\text { todos }\end{array}$ \\
\hline
\end{tabular}




\begin{tabular}{|c|c|}
\hline $\begin{array}{l}\text { sarróctenhé marrá iní óctenh aúsi } \\
\text { este quién\&sabe cómo se\&llama perro }\end{array}$ & quién sabe cómo se llama el perro \\
\hline $\begin{array}{l}\text { pá itonhé maúra rrijué maráme maurajá aúsi } \\
\text { ya vino grave hizo plural grave perro }\end{array}$ & $\begin{array}{l}\text { vino grave el perro por lo que le } \\
\text { hicieron }\end{array}$ \\
\hline $\begin{array}{l}\text { rrijué maráme córayú } \\
\text { hizo plural palo\&con }\end{array}$ & lo que le hicieron con un palo \\
\hline $\begin{array}{l}\text { tacá rricué tafính maráme } \\
\text { entonces matar dejó plural }\end{array}$ & y lo dejaron muerto \\
\hline
\end{tabular}

Segunda persecución: persecución con armas y nueva victoria de los malecus por medio de una acción mágica

\begin{tabular}{|c|c|}
\hline $\begin{array}{l}\text { tacá iója chumá mará córa quiója } \\
\text { entonces corrieron pobre plural árbol hacia }\end{array}$ & $\begin{array}{l}\text { y los pobres corrieron hacia el } \\
\text { bosque }\end{array}$ \\
\hline $\begin{array}{l}\text { chumá maráme pá itúe mará } \\
\text { pobre plural ya fue plural }\end{array}$ & los pobres se fueron \\
\hline $\begin{array}{l}\text { tacán túcja chiúti maráma ferrferréca itúcja } \\
\text { entonces tras no\&malecu plural tiraban\&y\&tiraban } \\
\text { tras\&ellos }\end{array}$ & $\begin{array}{l}\text { entonces los no indígenas se fueron } \\
\text { tras ellos y les tiraban y les tiraban }\end{array}$ \\
\hline $\begin{array}{l}\text { iferrferréca maráma iquíta ninháfa rracuá jué } \\
\text { lacáchi malécu rricué } \\
\text { tiraba\&y\&tiraba plural querían también matarlos } \\
\text { en\&efecto uno malecu mataron }\end{array}$ & $\begin{array}{l}\text { y les tiraban y les tiraban y también } \\
\text { querían matarlos y en efecto } \\
\text { mataron a un malecu }\end{array}$ \\
\hline $\begin{array}{l}\text { tacá tacá amí enéque maráme iríjalánhe pá iró } \\
\text { entonces entonces otra\&vez otro plural regresaron } \\
\text { ya fueron }\end{array}$ & $\begin{array}{l}\text { entonces otra vez otros regresaron } \\
\text { y se fueron }\end{array}$ \\
\hline $\begin{array}{l}\text { tacá níni ní ióctenhé Córen malécu } \\
\text { entonces este\&es este se\&llama Coren malecu }\end{array}$ & ese se llama Coren en malecu \\
\hline $\begin{array}{l}\text { jué enéque tan marrá iná enéque óctenh } \\
\text { en\&efecto otro pero quién\&sabe cómo otro } \\
\text { se\&llama }\end{array}$ & $\begin{array}{l}\text { hay otro pero quién sabe cómo se } \\
\text { llama }\end{array}$ \\
\hline $\begin{array}{l}\text { tacá narriquí tacá ijá maráma ní rrijuéca sarrónh } \\
\text { entonces me\&dijeron entonces le plural este hicieron } \\
\text { este }\end{array}$ & eron que les hicieron \\
\hline $\begin{array}{l}\text { ninháfa yújaqui tócufá rríjoyé yújanh iquí } \\
\text { también pita mucho hicieron pita dice }\end{array}$ & $\begin{array}{l}\text { se dice que también hicieron } \\
\text { muchas plantas de pita }\end{array}$ \\
\hline $\begin{array}{l}\text { tacá chí ijá maráma yújaquí irierrónhe chiúti ajá } \\
\text { entonces todo le plural pita pegaron no\&malecu para }\end{array}$ & $\begin{array}{l}\text { y las plantas de pita se les pegaron } \\
\text { todas a la piel a los no malecus }\end{array}$ \\
\hline $\begin{array}{l}\text { tacá chí chiúti joquí rriarínhe malécu maráma } \\
\text { iriliú ní járifa ninháfa } \\
\text { entonces todo no\&malecu cara perdieron malecu } \\
\text { plural por\&causa\&de este responsable también }\end{array}$ & $\begin{array}{l}\text { entonces los malecus mataron a } \\
\text { todos los no malecus por causa de } \\
\text { este responsable también }\end{array}$ \\
\hline \multicolumn{2}{|c|}{$\begin{array}{c}\text { Conclusión: victoria de Colón, robo del oro, asesinato de malecus y digresión sobre } \\
\text { la identidad de Colón }\end{array}$} \\
\hline $\begin{array}{l}\text { tacá malécu rricuécué tóye ní riliúca Cristóbal } \\
\text { Colón }\end{array}$ & $\begin{array}{l}\text { entonces Cristóbal Colón fue } \\
\text { matando y matando a los malecus }\end{array}$ \\
\hline
\end{tabular}


entonces malecu matar\&y\&matar fue este

responsable Cristóbal Colón

tacá am tacá am malécu maráma chí rricuáca

entonces otra\&vez entonces otra\&vez malecu plura todos mató

chí quí cóne sarróqui rricúye todo dice en\&perjuicio este agarró

ó te sarróctenhé oro iquí cóne maráma chí rricúye se dice que les quitó todo el oro que este oro dice en\&perjuicio plural todo agarró

\begin{tabular}{|c|c|}
\hline $\begin{array}{l}\text { tacá iyú tóye } \\
\text { entonces con\&él fue }\end{array}$ & y se lo llevó \\
\hline $\begin{array}{l}\text { tacá márra ménhe ní ó chiúti ó riliúca márra } \\
\text { ménhe pucsufa } \\
\text { entonces quién\&sabe dónde este que no\&malecu } \\
\text { que responsable quién\&sabe dónde vive }\end{array}$ & $\begin{array}{l}\text { quién sabe de dónde es ese no } \\
\text { malecu, el responsable, quién sabe } \\
\text { dónde vive }\end{array}$ \\
\hline $\begin{array}{l}\text { epéme ní maurájecá márrapé Nicaragua carráco } \\
\text { sarróctenhé } \\
\text { no este quién\&sabe seguramente Nicaragua en este }\end{array}$ & $\begin{array}{l}\text { no se sabe, seguramente de } \\
\text { Nicaragua }\end{array}$ \\
\hline $\begin{array}{l}\text { marrá irrióctenh Cristóbal Colón márrapé } \\
\text { Nicaragua carráco púcsufá epéme ní maurájecá } \\
\text { márrame púcsuf } \\
\text { quién\&sabe se\&llama Cristóbal Colón quién\&sabe } \\
\text { Nicaragua en vive no este se\&sabe dónde vive }\end{array}$ & $\begin{array}{l}\text { quién sabe cómo se llama, } \\
\text { Cristóbal Colón seguramente vive } \\
\text { en Nicaragua, no se sabe dónde } \\
\text { vive }\end{array}$ \\
\hline $\begin{array}{l}\text { tacán chí malécu maráma rricuéquecuéque tué } \\
\text { entonces todo malecu plural matar\&y\&matar fue }\end{array}$ & $\begin{array}{l}\text { fue matando y matando a todos los } \\
\text { malecus }\end{array}$ \\
\hline
\end{tabular}

Fuente: Elaboración propia.

El segundo texto fue documentado con don Eustaquio Castro Castro, adulto mayor de más de 70 años, originario del poblado de Margarita, y gran conocedor de toda la tradición de su pueblo. En este caso solo se ofrece la transcripción en malecu y la respectiva traducción libre aproximada al español. Claramente, la tensión narrativa en este relato es muy distinta a la del anterior, por lo que no se encuentra la mayoría de los recursos léxico-gramaticales comentados.

Nótese, eso sí, que los etnónimos para referirse a todos los demás pueblos indocostarricenses son tomados del español (bribri, boruca, térraba, teribe, guaymí, talamanqueño), pues en la lengua malecu no existen términos patrimoniales al respecto (Tabla 2). Ello constituye una pista lingüística de que los malecus no mantenían contacto con 
estos grupos, como sí con los botos, para quienes existe un etnónimo patrimonial (póto) y un ciclo narrativo (Constenla e Ibarra, 2014). La importancia de este dato se verá más adelante.

Tabla 2. Texto 2, sobre la guerra de los españoles contra pueblos indígenas

\begin{tabular}{|c|c|}
\hline \multicolumn{2}{|l|}{ Texto 2} \\
\hline $\begin{array}{l}\text { Níni nílha ricunúca maráma chiúti maráma tocá } \\
\text { carrtaúni ní ripilájucáco }\end{array}$ & $\begin{array}{l}\text { Esto es lo que se escucha sobre los } \\
\text { no malecus; vinieron de lejos de } \\
\text { muy lejos }\end{array}$ \\
\hline $\begin{array}{l}\text { táni quí nefarú tafínhe epéme nicó yají anh maráme } \\
\text { unhúti tói napúca nicó ucúriclhá nefarú itafính } \\
\text { maráme ó carráco ní maráma pucá bribri maráma ófa } \\
\text { buruca carráco eh térraba carráco emé ní ó yají anh } \\
\text { mará }\end{array}$ & $\begin{array}{l}\text { pero se dice que allá se quedaron, } \\
\text { aquí no llegaron donde vivimos } \\
\text { nosotros aquí en Guatuso; se } \\
\text { quedaron allá donde viven los } \\
\text { bribris y los borucas, térrabas; aquí } \\
\text { no llegaron }\end{array}$ \\
\hline $\begin{array}{l}\text { tan quí maráme chífa orróquiyu maíca maráma tóye } \\
\text { ó tóculhá ipucá ó chiútiti iónhe oro níyu chí tué } \\
\text { maráme }\end{array}$ & $\begin{array}{l}\text { pero dicen que los diablos se } \\
\text { llevaron todas las cosas del lugar } \\
\text { del dios, lo que los chiúti llaman el } \\
\text { oro, se llevaron todo }\end{array}$ \\
\hline $\begin{array}{l}\text { tacá malécu marámajá ó lécu lhíja maráma ní } \\
\text { rritáye nocófa iquí maráme pélho o este espejo }\end{array}$ & $\begin{array}{l}\text { entonces les dieron a los malecus, a } \\
\text { los grupos indígenas les dieron en } \\
\text { verdad un espejo }\end{array}$ \\
\hline $\begin{array}{l}\text { tacá curíjuríu tué maráme arapcháu tué maráme } \\
\text { ochápacáu tué maráme iná mapaí nocó ianhé pucá } \\
\text { mará }\end{array}$ & $\begin{array}{l}\text { entonces se llevaron a mujeres, a } \\
\text { niños, a hombres imposible que } \\
\text { dejen de hacer lo que están } \\
\text { haciendo }\end{array}$ \\
\hline $\begin{array}{l}\text { tacá jué malécu jué ní rricuá maráme boruca } \\
\text { carraconhé maráma }\end{array}$ & $\begin{array}{l}\text { entonces los *malecus mataron a } \\
\text { los borucas } \\
(* \text { error: se refiere a los no malecus })\end{array}$ \\
\hline ófa ní bribri carraconhé mará chí jué ní rricúecúe & $\begin{array}{l}\text { y los bribris a todos los mataban y } \\
\text { mataban }\end{array}$ \\
\hline táni iquí quí jué ní punhé cacique & pero dicen que había un cacique \\
\hline $\begin{array}{l}\text { táni iquí epéme tói nicó ucúrucja ní anhé cacique } \\
\text { nefarú punhé Talamanca }\end{array}$ & $\begin{array}{l}\text { pero dicen que aquí en Guatuso no } \\
\text { había cacique, solo allá en } \\
\text { Talamanca }\end{array}$ \\
\hline $\begin{array}{l}\text { eh téribe maráma guaymí maráma epéme nicó ní } \\
\text { maráma anhé ní maráma sarróqui maráma cacique } \\
\text { maráma }\end{array}$ & $\begin{array}{l}\text { en el lugar de los teribes, de los } \\
\text { guaymíes, aquí no hay caciques }\end{array}$ \\
\hline $\begin{array}{l}\text { nífaru ní quí púnhe ó chiúti marámati iónhe } \\
\text { clarividente ó tócu cuácsuf ó tócu lhóqui cuácsufá ó } \\
\text { tócuyu jaícsuf }\end{array}$ & $\begin{array}{l}\text { se dice que solo hay lo que los no } \\
\text { malecus llaman clarividente, el } \\
\text { que ve a dios, el que ve al } \\
\text { divinizado y el que habla con dios }\end{array}$ \\
\hline
\end{tabular}




\begin{tabular}{|c|c|}
\hline marrá iná ipsóta maráme epéme ní ó yáji anh maráme & $\begin{array}{l}\text { no sé qué les pasó que no llegaron } \\
\text { acá }\end{array}$ \\
\hline $\begin{array}{l}\text { iquí maráme epéme ní ó itonhé puráni níti quíye ó } \\
\text { fújinhé iquíma nénhe Quitirrisí carráconh epéto ní ó } \\
\text { mitonh }\end{array}$ & $\begin{array}{l}\text { dicen que no se metieron aquí } \\
\text { porque les dijo el que manda, el de } \\
\text { Quitirrisí: "no vengan acá }\end{array}$ \\
\hline $\begin{array}{l}\text { puráni nánocó iyú malécu maráma itinínhe ipujíca } \\
\text { epéme póti ní maráma cuánhe nína acánhe }\end{array}$ & $\begin{array}{l}\text { porque los malecus no van a estar } \\
\text { jugando con ustedes; ellos son } \\
\text { otros }\end{array}$ \\
\hline $\begin{array}{l}\text { niní maráma epéme ninhánhe tiá tói acá tói ná acá tói } \\
\text { jué nanhé júe tói natémac }\end{array}$ & $\begin{array}{l}\text { estos son ellos, no como nosotros } \\
\text { somos diferentes, nosotros tenemos } \\
\text { misericordia }\end{array}$ \\
\hline $\begin{array}{l}\text { epéme tói napcuá suírre tan iná nocó miú ní maráma } \\
\text { tinínhe pujíca chíma }\end{array}$ & $\begin{array}{l}\text { nosotros no matamos de verdad, } \\
\text { pero ellos no van a estar jugando } \\
\text { con todos ustedes }\end{array}$ \\
\hline $\begin{array}{l}\text { carúcuné mirriafára maráma mapurú coné nánoco } \\
\text { itinínhe pujíca maráma }\end{array}$ & $\begin{array}{l}\text { los esperarían con flechas, lanzas; } \\
\text { no van a estar jugando" }\end{array}$ \\
\hline $\begin{array}{l}\text { tacá epéme nicó anhé tói nanhúti ucuriclhanhé lhíja } \\
\text { maráma tiá tói ó ó ó cacique maráma }\end{array}$ & $\begin{array}{l}\text { entonces aquí no hay donde } \\
\text { nosotros guatuseños como nosotros } \\
\text { caciques }\end{array}$ \\
\hline órrom nifáru punhé ó tócu cuacsufá ó atacá acsufá & nada, solo clarividente y dios \\
\hline $\begin{array}{l}\text { emé ní maráma tininhé pují tan níyu malécu maráma } \\
\text { jóqui rriarré cólocomá }\end{array}$ & $\begin{array}{l}\text { ellos no están jugando pero con } \\
\text { estos los malecus ganaron el collar }\end{array}$ \\
\hline $\begin{array}{l}\text { tamá cólocómati quí jué cuérrelhá maráma toquí } \\
\text { tónh ílha urúje maráma naícoti ajá malhorónhyu } \\
\text { mibafáfá }\end{array}$ & $\begin{array}{l}\text { y el collar les dice: "vienen los no } \\
\text { indígenas, avanzando los no } \\
\text { indígenas; ahí rieguen la manteca } \\
\text { de cacao" }\end{array}$ \\
\hline $\begin{array}{l}\text { tacá rriquí iyú mibafafá ta tóiti lhóqui chirríqui tató } \\
\text { nicó inórra calíco fatáru ní tícte córa chalhac }\end{array}$ & $\begin{array}{l}\text { y les dijo: "riéguenla para nosotros } \\
\text { resbalarlos y aquí dentro de la } \\
\text { garganta solo se les entierra una } \\
\text { estaca" }\end{array}$ \\
\hline $\begin{array}{l}\text { puráni epéme pué malécu maráma tiní cuánhe ní } \\
\text { maráma ó maráma tonhé né ní ripilajucáco itocá } \\
\text { maráma iquí maráme atá ní ó majuríma }\end{array}$ & $\begin{array}{l}\text { porque ellos no quieren a los } \\
\text { malecus, ellos los que vienen en } \\
\text { caminos ondulados vienen y dicen } \\
\text { para visitar acá }\end{array}$ \\
\hline taíclhacá ní rricuá malécu maráma ó lécu mará & $\begin{array}{l}\text { mataron a demasiados malecus, } \\
\text { indígenas }\end{array}$ \\
\hline $\begin{array}{l}\text { ní nacánhe tói epéme iná ní tótiquí majóye ó maráma } \\
\text { tonhé carrtaúni acáta }\end{array}$ & $\begin{array}{l}\text { esos otros no son nosotros, ellos no } \\
\text { nos han hecho nada, los que vienen } \\
\text { de lejos, los extranjeros }\end{array}$ \\
\hline tacá ní maráma anh iná tiánh maráma & allá ellos cómo se van a conducir \\
\hline $\begin{array}{l}\text { Tacá ninhá ipunh maráme iricúe unh maráme malécu } \\
\text { ní maráma talamanca ófa térraba carráconhé mará }\end{array}$ & $\begin{array}{l}\text { y así se pasaban matando los } \\
\text { indígenas, los talamancas y los } \\
\text { térrabas }\end{array}$ \\
\hline emé tinínhé pují maráme níca nícanh ní maráma itaté & $\begin{array}{l}\text { no estaban jugando estos, } \\
\text { demasiados demasiados muertos }\end{array}$ \\
\hline
\end{tabular}




\begin{tabular}{|c|c|}
\hline $\begin{array}{l}\text { irricuánhe ó carrtaúninhá tócsufá mará epéme ésa } \\
\text { icarráco iptáiquinh nína }\end{array}$ & $\begin{array}{l}\text { veían a los que venían de lejos, } \\
\text { poco les importaba }\end{array}$ \\
\hline $\begin{array}{l}\text { atácachá iucá maráma ní maráma ó lécu maráma né } \\
\text { Térraba mará ófa nénhe maráma sarróqui carráconhé } \\
\text { Talamanca acá ní maráma unhé sarróqui maráma } \\
\text { cabécar mará }\end{array}$ & $\begin{array}{l}\text { estaban solos esos indígenas de } \\
\text { Térraba y los de Talamanca, aparte } \\
\text { estaban los cabécares }\end{array}$ \\
\hline $\begin{array}{l}\text { táni quí maráme cabécar maráma ní maráma jóqui } \\
\text { rriarré unh }\end{array}$ & $\begin{array}{l}\text { pero dicen que los cabécares } \\
\text { estaban ganando }\end{array}$ \\
\hline $\begin{array}{l}\text { ninháfa jué ninháta ipunh maráme nápenápe anh } \\
\text { mará }\end{array}$ & $\begin{array}{l}\text { hasta el momento siguen igual } \\
\text { conduciéndose mal }\end{array}$ \\
\hline $\begin{array}{l}\text { iquí tacá ninháfa ianh maráme malécu maráma eh } \\
\text { lécu maráma bribri carraconhé mará }\end{array}$ & $\begin{array}{l}\text { dicen que también así hacían los } \\
\text { malecus eh los indígenas bribris }\end{array}$ \\
\hline $\begin{array}{l}\text { epéme tinínhe pují maráme níca nícanh chiúti } \\
\text { maráma rricuá maráme }\end{array}$ & $\begin{array}{l}\text { no estaban jugando, mataban } \\
\text { demasiados chiúti }\end{array}$ \\
\hline $\begin{array}{l}\text { taca am tóye Cristóbal Colón ó carráco ipucá tacá níu } \\
\text { tonhé nícanh curíjurí mará }\end{array}$ & $\begin{array}{l}\text { y Cristóbal Colón se fue otra vez } \\
\text { adonde él vivía y volvió con } \\
\text { muchas mujeres }\end{array}$ \\
\hline $\begin{array}{l}\text { tan ní maráma quí talamanqueño maráma juéto tóiti } \\
\text { cuá ní curíjurí mará }\end{array}$ & $\begin{array}{l}\text { pero dijeron los talamanqueños: } \\
\text { "nosotros vamos a matar a estas } \\
\text { mujeres" }\end{array}$ \\
\hline $\begin{array}{l}\text { táni maráláfarinhánhe mará ní maráma ó marámau } \\
\text { tonh }\end{array}$ & $\begin{array}{l}\text { pero son demasiado bellas esas } \\
\text { que trajeron }\end{array}$ \\
\hline $\begin{array}{l}\text { táni me tinínhe pují maráme bribri maráma tacá jué } \\
\text { chí ní rricuá maráme curíjurí iquí maráme óyu } \\
\text { ninháfa toí nalécu rrijué mará }\end{array}$ & $\begin{array}{l}\text { pero no estaban jugando los bribris } \\
\text { y mataron a todas las mujeres, } \\
\text { dijeron que por eso mataron } \\
\text { también a nuestra gente. }\end{array}$ \\
\hline
\end{tabular}

Fuente: Elaboración propia

\section{Los malecus contra Colón: ¿anacronismo o retradicionalización?}

En esta sección comentamos someramente algunos detalles de los textos documentados y proponemos cómo se pueden comprender y apreciar mejor si se consideran como productos de un proceso de reelaboración, reinterpretación y retradicionalización, en lugar de juzgar su exactitud histórica desde la óptica de la historiografía exocomunitaria.

El primer texto ejemplifica el dinamismo de la tradición oral al fundir el recuerdo de acontecimientos guardados en la memoria colectiva del pueblo (el genocidio causado por los huleros) con datos adquiridos más recientemente (aunque en realidad se refieren a tiempos 
más remotos). El segundo texto podría contener el residuo de una tradición antigua (los posibles relatos que sobre los forasteros europeos llegaron a los malecus, debido a su interacción con otros grupos indígenas con los que presuntamente sí tuvieron contacto durante la Colonia), si bien ha sido reelaborado con información proveniente de fuentes externas modernas (como el nombre de los pueblos involucrados en la guerra) y también parece recoger información propia de un texto sobre los huleros (tacá curíjuríu tué maráme arapcháu tué maráme ochápacáu tué maráme 'entonces se llevaron a mujeres, a niños, a hombres'). En ambos, se sitúa a Colón como cabecilla de la conquista del actual territorio costarricense.

Si cotejamos estos textos de tradición oral con los documentos históricos hispanos, concluiríamos que en ambos se plasman múltiples anacronismos (por ejemplo, Colón no incursionó en territorio malecu ni tuvo ningún tipo de contacto con estos), por no mencionar información contraria a la recogida en la historiografía hispana (por ejemplo, que Colón de hecho no participó en la conquista del actual territorio costarricense, la cual en realidad es muy tardía: 1561 para el Valle Central; ver Solórzano y Quirós, 2006), sin olvidar otros datos que no coinciden con lo que sabemos de la cultura malecu (por ejemplo, no parece que trabajaran el oro).

No obstante, si nos situamos en la perspectiva del funcionamiento de la tradición oral, los textos muestran en realidad cómo actúan los procesos regulares de la tradicionalización y de la retradicionalización: reconfiguración del pasado de modo selectivo en función de las prioridades y conocimientos del presente, surgimiento de nuevas versiones a partir de variaciones de un tema construidas sobre motivos equivalentes, estabilidad de un núcleo narrativo básico con detalles en cambio continuo, así como síntesis creativa de varias versiones por parte del narrador (Vas da Silva, 2014). 
La tradición oral no es estática, sino todo lo contrario. Si bien existe estabilidad temática, la tradición se transforma de modo que los antiguos temas evolucionan en el proceso de transmisión intergeneracional en el cual las variaciones están a la orden del día (Vas da Silva, 2014). Es un hecho constatado que la tradición oral existe, por lo tanto, en múltiples versiones. Al respecto, Thompson (1946) reseña algunos de los principios de Anderson para dar cuenta de tal variación, tales como la adición de un detalle originalmente ausente, el cual puede proceder de otro relato o ser inventado; la fusión de dos o más relatos; la sustitución de episodios de un relato por los de otro; la necesidad de mayores cambios en una narración con el fin de mantener su consistencia una vez que se introdujo una variación; así como la adaptación a un nuevo entorno y a nuevas circunstancias, entre otros. Por ello, Vas da Silva (2014) sostiene que las tradiciones constituyen procesos de final abierto cuya configuración está determinada por la interacción entre las variaciones introducidas por el individuo y los mecanismos de selección comunitarios, y sugiere que toda tradición se puede concebir como una especie de palimpsesto.

Los textos documentados sobre la relación de Colón con los malecus no deben examinarse, por ende, en búsqueda de la exactitud histórica acerca de la Conquista y sus consecuencias para los pueblos nativos de la región. No se trata de relatos de acontecimientos documentados en la historiografía hispánica, sino de la visión -reelaborada, reconstruida, reinterpretada- acerca de un hito que cambió el orden social prevaleciente. Por lo tanto, el Colón de estos relatos no es la figura histórica de Colón, sino una especie de epítome de los conquistadores no indígenas, quienes son considerados sujetos que tan solo buscan apoderarse del oro de los pueblos nativos y que avanzan en su propósito exterminando a 
todos los pueblos indocostarricenses en general, en un relato, y a los malecus en particular, en el otro. ${ }^{1}$

Ciertamente, en su cuarto viaje a América, en 1502, Colón exploró la costa atlántica del actual territorio costarricense en su empeño por encontrar una vía de paso del Caribe a la India (el llamado "estrecho dudoso") en el istmo centroamericano. Colón y los expedicionarios que lo acompañaban fueron recibidos amistosamente por algunas poblaciones, pero sufrieron la resistencia de otras, especialmente a causa de los comportamientos ultrajantes que prontamente mostraron hacia estas. Empero, lograron obtener por trueque y por saqueo algunos objetos de oro y ello trastocó sus intenciones: a partir de ese momento su objetivo principal consistió en hallar yacimientos de este metal, propósito que no se logró cumplir, pero que los motivó a proseguir la exploración de las localidades situadas a lo largo de la costa caribe. En su travesía, los acompañantes de Colón arrasaron con campos de maíz y se ganaron la enemistad de las poblaciones locales, pero no dieron con el paradero ni del estrecho dudoso ni de los anhelados yacimientos auríferos (Solórzano y Quirós, 2006).

En cualquier caso, desde la perspectiva malecu, no es de extrañar que se hagan converger, en la primera historia, acontecimientos que recuerdan más la invasión del territorio malecu por parte de los huleros, en la segunda mitad del siglo XIX, con la exploración de territorios por parte de Colón y sus acompañantes en busca de oro, a inicios del siglo XVI. Ambos sucesos ocurrieron, si bien con una distancia temporal de más de tres

\footnotetext{
${ }^{1}$ No obstante, bien podría ser que en el primer texto malécu se refiera a los indígenas en general también. Es común en la actualidad que, pese a que, en principio, el etnónimo malécu solo aluda al grupo propio y que lécu se emplee para referirse a otros grupos originarios, los malecus uticen el etnónimo malecu (al menos cuando hablan español) como equivalente al panetnónimo "indígena" y que especifiquen el lugar de proveniencia: "Es un malecu de Quitirrisí”, "es una malecu de Talamanca” (Sánchez, 2015).
} 
siglos y medio. Los protagonistas foráneos son distintos: los expedicionarios europeos en el siglo XVI y los huleros nicaragüenses (y posiblemente del norte de Costa Rica también) en el siglo XIX. El propósito de la invasión también difiere: Colón buscaba oro (y el estrecho dudoso), mientras que los huleros deseaban explotar y comerciar la savia del caucho. Más allá de estas divergencias desde el punto de vista de la historiografía hispánica, destaca una coincidencia: la afectación a las poblaciones locales, las cuales son víctimas de maltrato y exterminio de parte de individuos de cultura y lengua española dispuestos a cometer cualquier vejación y apoderarse de los recursos necesarios con tal de satisfacer sus ambiciones.

Desde la perspectiva de una población como la malecu, la conquista que acabaría con su organización socio-política y con su sistema de subsistencia fue perpetrada por la misma categoría de individuos, denominados chiúti (o cuérrelhá maráma e ílha urúje maráma, en el segundo texto), tanto de si se trata de españoles como de nicaragüenses o costarricenses. El etnónimo únicamente se refiere a aquel que no es malecu ni originario de otro grupo nativo del territorio; es decir, con este etnónimo se alude al "Otro" por antonomasia, aquel con quien no se comparten ni la lengua ni la cultura, el forastero con quien posteriormente se construirá la frontera etnoidentitaria que perdura hasta nuestros días. ${ }^{2}$

En la visión de los antiguos malecus, no habría discontinuidad en la identidad del grupo invasor (los conquistadores españoles son iguales a los huleros) ni tampoco existiría anacronismo en cuanto a cuándo ocurrieron los acontecimientos relatados, puesto que lo relevante es que se produjo la conquista del territorio, cuyo objetivo consistió en apropiarse

\footnotetext{
${ }^{2}$ Cabe destacar que lo mismo ocurre en otras lenguas indocostarricenses, como el bribri, el cabécar, el naso y el brunca. En brunca, por ejemplo, también se documentaron narraciones sobre el enfrentamiento de los borucas con los conquistadores españoles, a quienes se alude como siv cua rájc. El término sîv cua se refiere a los no indígenas, sean estos los españoles, como en los relatos aludidos, o los hispanocostarricenses actuales (Constenla y Maroto, 1979).
} 
de sus riquezas, y ello implicó enfrentamientos bélicos y exterminios. Poco importa que Colón no haya tenido nada que ver directamente con ellos, que posiblemente no hayan trabajado el oro y que los conquistadores europeos se sitúen en el período de la Conquista y de la Colonia, mientras que los huleros hayan actuado ya durante las primeras décadas de la República, todo esto desde la periodización de la historia costarricense construida por el grupo de lengua y cultura española.

La retradicionalización ha operado, en el caso de los dos textos documentados, fundiendo dos momentos temporalmente distintos -desde la perspectiva exocomunitariadebido a la coincidencia de la identidad de los involucrados (invasores foráneos), los objetivos (expoliación de riquezas) y las consecuencias (genocidio y desestructuración del orden social imperante). Podría ser que, como en el caso del relato sobre fray Tomás López recogido en Betancourt y Constenla (1981), se trate de historias muy antiguas que aludían en efecto a las actuaciones de los conquistadores españoles y que se llegaron a conocer entre los malecus debido a su contacto con otras poblaciones nativas, sobre todo si realmente algunos sujetos escapados llegaron a refugiarse entre ellos.

Si esto ocurrió así, con el pasar de los años se fueron incorporando detalles aprendidos por el conocimiento de la historia hispanocostarricense y lo que ha llegado hasta nuestros días son versiones reelaboradas en las que el conquistador se denomina Cristóbal Colón y se le atribuye la debacle social, así como el robo del oro, pero ambas conservarían igualmente detalles de relatos antiguos y propios de la narrativa tradicional malecu, como los relacionados con eventos mágicos o extraordinarios que hacen cambiar el rumbo de los acontecimientos. $^{3}$

\footnotetext{
${ }^{3}$ En particular, el colócoma es un elemento muy conocido de los maracunúca malecus. Incluso existe un relato muy popular perteneciente al ciclo narrativo sobre los felinos. En este, dos hombres acuerdan salir a cazar al
} 
No se trataría de casos aislados. De hecho, existe evidencia de que este proceso de reelaboración e incorporación de nuevos detalles en las narraciones tradicionales malecus ha ocurrido otras veces. No solo se pueden mencionar los ya aludidos relatos sobre la incursión de fray Tomás López al territorio malecu, sino incluso una narración perteneciente al ciclo narrativo Ní lha irícunúca ó chiúja ianhé ucá maráma '(lo que) se ha escuchado sobre cómo se estuvieron conduciendo antiguamente', que versa acerca de la llegada de los Dioses, la creación de la humanidad, la transformación de la tierra y el destierro del Sol, entre otros acontecimientos (Constenla, Castro y Blanco, 1993). En particular, la narración sobre el destierro del Sol, un ser antropomorfo, muy blanco y barbado, muestra claramente cómo con toda seguridad se modificó un relato mítico antiguo para dar cabida a una explicación sobre la situación presente.

En esta narración, los Dioses malecus y los seres humanos intentaban averiguar qué comía el Sol, dado que rechazaba todos los alimentos que se le ofrecían. Uno de los Dioses le dio a beber sangre humana, la cual este consumió con muchas ganas. Esta conducta alertó a los Dioses y por ello se decidió subirlo al cielo. En el ínterin, el Sol, asimilado ya al Dios de los chiúti, intenta persuadir a los Dioses malecus de que no lo expulsen a cambio de proporcionarles a los malecus las mismas tecnologías de que gozaban sus criaturas (menciona los cuchillos para trabajar bien, medios de transporte terrestre y aéreo). Ante la negativa de estos, el Sol augura los infortunios que padecerán los malecus: morir por mordeduras de culebra, ahogados o devorados por felinos; andar desnudos; ser pocos.

siguiente día. Esto lo escucha un felino, quien en la noche se come a uno de ellos, adopta su figura en la mañana y sale a cazar con el otro hombre. Este porta un colócoma, que no solo le revela la verdadera identidad de su acompañante, sino que lo previene de no aceptarle los alimentos que este le ofrecerá posteriormente (los dedos de su amigo), le indica cuándo atacarlo una vez que el otro adopta forma de felino -aunque no pudo matarloy, finalmente, le aconseja esperar a que se duerma para asesinarlo (Constenla y Castro, 2011). 
Los Dioses malecus replican vaticinando el mal para los chiúti: matarse entre sí con cuchillos, morir en guerras, no beber chocolate, no bañarse y tener mal olor. Como finalmente el Sol fue desterrado, se cumplieron todas las predicciones (Constenla, Castro y Blanco, 1993). De esta forma, se reelaboró un mito con el fin de incluir la explicación de la desigualdad entre malecus e hispanos, así como las distintas formas de vivir y de perecer de ambos, a partir de un filtro interpretativo contemporáneo que, entre otros aspectos, los habría convencido de que, si no se vestían a la usanza de los forasteros, andarían desnudos, así como de que eran demográficamente más reducidos.

\section{Conclusión}

En síntesis, los textos malecus sobre Cristóbal Colón documentados y comentados en los párrafos anteriores aportan evidencia acerca del dinamismo de la tradición oral. Se trata de síntesis creativas de relatos sobre momentos históricos distintos desde la perspectiva historiográfica hispanocostarricense (la llegada de Colón a inicios del siglo XVI, la conquista del actual territorio costarricense en la segunda mitad del siglo XVI y el genocidio malecu perpetrado por los huleros en la segunda mitad del siglo XIX), pero versan acerca de acontecimientos analogables en cuanto a la configuración etnoidentitaria de los participantes de la narración (los malecus y otros indígenas frente a los no indígenas), las intenciones (la apropiación por la fuerza de un bien que pertenece a otro grupo) y el procedimiento (el exterminio de las poblaciones locales). Los relatos en cuestión, por lo tanto, se mantienen fieles al tema central, se trate de la época de los huleros o de la época de la Conquista: el exterminio de los malecus y el robo de sus bienes materiales. 


\section{Referencias bibliográficas}

Betancourt de Sánchez, H. y Constenla Umaña, A. (1981). La expedición al territorio de los guatusos: una crónica colonial hispana y su contraparte en la tradición oral indígena. Revista de Filología y Lingüística, 7(1-2), 19-34.

Boza Villarreal, A. y Solórzano Fonseca, J. C. (2000). El Estado nacional y los indígenas: el caso de Talamanca y Guatuso. Costa Rica, 1821-1910. Revista de Historia, 42, 4579.

Castillo Vásquez, R. (2004). An Ethnogeography of the Maleku Indigenous Peoples in Northern Costa Rica. [Tesis doctoral, University of Kansas].

Castillo Vásquez, R. (2005). Población indígena maleku en Costa Rica. Anuario de Estudios Centroamericanos, 31, 115-136.

Constenla Umaña, A. (1988). El guatuso de Palenque Margarita: su proceso de declinación. Estudios de Lingüística Chibcha, 7, 7-37.

Constenla Umaña, A. (1996). Poesía tradicional indígena costarricense. San José, Costa Rica: Editorial de la Universidad de Costa Rica.

Constenla Umaña, A. (1998). Gramática de la lengua guatusa. Heredia, Costa Rica: Editorial de la Universidad Nacional.

Constenla Umaña, A., Castro, E. y Blanco, A. (1993). Laca Majifijica. La transformación de la tierra. San José, Costa Rica: Editorial de la Universidad de Costa Rica.

Constela Umaña, A. y Castro Castro, E. (2011). Pláticas sobre felinos. San José, Costa Rica: Editorial de la Universidad de Costa Rica.

Constenla Umaña, A. y Ibarra Rojas, E. (2014). Anotaciones etnohistóricas sobre los indígenas botos: confluencia de datos históricos, antropológicos y de la tradición oral malecu. Estudios de Lingüística Chibcha, 33, 111-164.

Constenla Umaña, A. y Maroto, E. S. (1979). Leyendas y tradiciones borucas. San José, Costa Rica: Editorial de la Universidad de Costa Rica.

Edelman, M. (1998). Un genocidio en Centroamérica: hule, esclavos, nacionalismo y la destrucción de los indígenas guatusos-malecus. Mesoamérica, 36, 539-591.

Fernández, L. (1883). Colección de documentos para la Historia de Costa Rica. Tomo III. San José, Costa Rica: Imprenta Nacional. 
Fernández, L. (1907). Colección de documentos para la Historia de Costa Rica (Tomo IX). Barcelona, España: Imprenta Viuda de Luis Tasso.

Porras Ledesma, Á. (1959). El idioma guatuso: fonética y lexicología. [Tesis de licenciatura, Universidad de Costa Rica].

Sánchez Avendaño, C. (2015). La cola de la iguana. El pueblo malecu frente al desplazamiento de su lengua y su cultura tradicional. San José, Costa Rica: Editorial de la Universidad de Costa Rica.

Sapper, K. (1942). Viajes a varias partes de la República de Costa Rica 1899 y 1924. San José, Costa Rica: Imprenta Nacional.

Solórzano Fonseca, J. C. (1997). Indígenas insumisos, frailes y soldados: Talamanca y Guatuso, 1660-1821. Anuario de Estudios Centroamericanos, 23(1-2), 143-197.

Solórzano Fonseca, J. C. y Quirós Vargas, C. (2006). Costa Rica en el siglo XVI. Descubrimiento, exploración y conquista. San José, Costa Rica: Editorial de la Universidad de Costa Rica.

Thompson, S. (1946). The Folktale. Berkeley, Estados Unidos: University of California Press.

Vas da Silva, F. (2014). Tradition Without End. En R. Bendix y G. Hasan-Rokem (Eds.), A Companion to Folklore (pp. 40-54). West Sussex, Inglaterra: Wiley Blackwell. 